\title{
Liderança e gestão: um estudo em Organizações Não Governamentais (ONGs) na região metropolitana do Recife, $\mathrm{PE}$
}

\author{
Leadership and management: a study in Non-Governmental Organizations \\ (NGOs) in the metropolitan region of Recife, PE
}

\section{Liderazgo y gestión: un estudio en Organizaciones No Gubernamentales (ONGs) en la región metropolitana de Recife, $P E$}

\author{
Ana Paula Santana Melo ${ }^{1}$ \\ Marcelo da Costa Borba \\ Maria Irae Souza Correia ${ }^{1}$ \\ Romilson Marques Cabral ${ }^{1}$
}

Recebido em 16/07/2018; revisado e aprovado em 18/04/2019; aceito em 22/04/2018 DOI: http://dx.doi.org/10.20435/inter.v20i4.2077

\begin{abstract}
Resumo: O objetivo da pesquisa é analisar as relações entre a liderança, as práticas de gestão estratégica e a continuidade das Organizações Não Governamentais (ONGs). A pesquisa será qualitativa. A coleta de dados será realizada através de três técnicas: entrevistas semiestruturadas com os líderes das instituições, análise documental e aplicação de questionário com os líderes e colaboradores. A análise será feita em oito Organizações Não Governamentais que possuam sede no estado de Pernambuco. Como técnica de análise dos dados, foi utilizado o método de análise de discurso. Os resultados mostraram as relações da liderança transformacional e as práticas de gestão estratégica, entre alguns aspectos, com o claro entendimento das estratégias e a tradução dos objetivos para toda a instituição. Quanto às características de liderança carismática, foi identificada a capacidade elevada de comunicação, que permite direcionar a equipe aos objetivos. Ainda, foram observados os aspectos de liderança transacional que demonstram uma relação com os aspectos internos, acompanhamento das atividades, cumprimento das normas e monitoramento de erros e desvios cometidos pela equipe.
\end{abstract}

Palavras-chave: liderança; gestão; Organizações Não Governamentais.

Abstract: The objective of the research is to analyze the relationships between leadership, strategic management practices and the continuity of non-governmental organizations (NGOs). The research will be qualitative. Data collection will be performed through three techniques: semi-structured interviews with the leaders of the institutions, documentary analysis and questionnaire application with leaders and collaborators. The analysis will be done in eight non-governmental organizations with headquarters in the state of Pernambuco. As data analysis technique, the speech analysis method was used. The results showed the relationships of transformational leadership and strategic management practices, among some aspects, with the clear understanding of strategies and the translation of objectives for the entire institution. As for the charismatic leadership characteristics, the high communication capacity was identified, which allows the team to be directed to the objectives. We also observed aspects of transactional leadership that demonstrate a relationship with internal aspects, monitoring of activities, compliance with standards and monitoring errors and deviations committed by the team.

Keywords: leadership; management; non-governmental organizations.

Resumen: El objetivo de la investigación es analizar las relaciones entre el liderazgo, las prácticas de gestión estratégica y la continuidad de las Organizaciones No Gubernamentales (ONG). La investigación será cualitativa. La recolección de datos se realizará a través de tres técnicas: entrevistas semiestructuradas con los líderes de las instituciones; análisis documental y aplicación de cuestionario con los líderes y colaboradores. El análisis se realizará en ocho organizaciones no gubernamentales con sede en el estado de Pernambuco. Como técnica de análisis de datos, se utilizó el método de análisis del habla. Los resultados mostraron las relaciones de liderazgo transformacional y prácticas de gestión estratégica, entre algunos aspectos, con la comprensión clara de estrategias y la traducción de objetivos para toda la institución. En cuanto a las características de liderazgo carismático, se identificó la alta capacidad de comunicación, lo que permite que el equipo se dirija

\footnotetext{
${ }^{1}$ Universidade Federal Rural de Pernambuco (UFRPE), Recife, Pernambuco, Brasil.

2 Universidade Federal do Rio Grande do Sul (UFRGS), Porto Alegre, Rio Grande do Sul, Brasil.
} 
a los objetivos. También observamos aspectos del liderazgo transaccional que demuestran una relación con aspectos internos, actividades de monitoreo, cumplimiento de estándares y errores y desviaciones de monitoreo cometidos por el equipo.

Palabras claves: liderazgo; gestión; organizaciones no gubernamentales.

\section{INTRODUÇÃO}

O termo terceiro setor tem sua origem no contexto de que a sociedade civil está dividida em Primeiro Setor- Estado; Segundo Setor- mercado e empresas privadas; e o Terceiro Setorconstituído por organizações que, embora tenham natureza privada, não possuem fins lucrativos (ALBUQUERQUE, 2006). Segundo Landim (1993), fazem parte do Terceiro Setor os seguintes tipos de instituições: Organizações da Sociedade Civil ou sem fins lucrativos; Associações; Entidades Filantrópicas, Beneficentes ou de Caridade; Fundações; Organizações Não Governamentais. Devido à variedade de terminologia e heterogeneidade das metodologias e classificações das instituições que compõem o terceiro setor, para esta pesquisa iremos delimitar o estudo para Organizações Não Governamentais (ONGs).

O termo Organização Não Governamental trata de uma expressão antiga, nascida na ONU pós-guerra, e o termo ONG passou a ganhar visibilidade pública aos poucos nos últimos anos, tornando-se tema de trabalhos acadêmicos e configurando debates nos meios intelectuais brasileiros (LANDIM, 1993). É um termo frequentemente utilizado nos países em desenvolvimento para designar organizações que proporcionam o desenvolvimento econômico e social, tipicamente no nível comunitário e de base (MAÑAS; MEDEIROS, 2012). A denominação ONG tem uma característica de consenso geral: entidades privadas sem fins lucrativos; no entanto, juridicamente, as ONGs podem ser classificadas em dois tipos: associações e fundações. "Essas organizações caracterizam-se por serem privadas sem fins lucrativos, formais e autônomas e incorporam algum grau de envolvimento de trabalho voluntário" (FISCHER, 2002, p. 45-46).

Essas organizações atuam como elo entre a sociedade e o Estado. Isso faz com que os trabalhos das ONGs ganhem maior importância (TACHIZAWA; POZO; ALVES, 2012). Como resultado da efetividade de trabalhos exercidos por essas organizações, observa-se uma visão institucional diferenciada e a formação de novos padrões de liderança e comportamento organizacional. Apesar de tratar-se de organizações sem fins lucrativos, não possuem natureza pública, dessa forma, seus aspectos organizacionais singulares exigem da sua liderança uma atenção e qualificação específica na busca por mudanças (BASS, 1990). A liderança tem um papel significativo na gestão do desempenho organizacional, o qual é explicado pelo paradigma empírico, que considera a liderança uma habilidade de utilizar de modo eficaz as ferramentas de mobilização e ainda permite a utilização de técnicas para criar um ambiente favorável aos líderes e liderados, objetivando alcançar as metas da organização (OUIMET, 2002).

\section{DESENVOLVIMENTO}

\subsection{Terceiro setor e as Organizações Não Governamentais}

O Terceiro Setor é constituído por organizações privadas que produzem bens e serviços públicos e privados, sem fins lucrativos. Essas organizações têm natureza privada com finalidade pública. Seus objetivos são voltados para o desenvolvimento político, econômico, social e cultural do meio onde atuam, ao passo que as ações estão focadas em temas como: cidadania, emancipação, autonomia e direitos da população, preferencialmente de excluídos e marginaliza- 
dos socialmente (FERNANDES, 1994). A natureza desse setor abrange amplamente instituições filantrópicas, organizações religiosas, organizações comunitárias, entidades voltadas para as artes, sindicatos, associações profissionais e outras organizações voluntárias. As ONGs surgiram sob a influência do assistencialismo, da caridade e da solidariedade. Na década de 1950, foram criados, pelos Estados Unidos, os primeiros fundos de assistência para as ONGs do Terceiro Mundo e, nos anos 1970, foi criada a Assistência Oficial para o Desenvolvimento (ODA) (BEZERRA; ARAÚJO, 2004).

No Brasil, as Organizações Não Governamentais tiveram participação decisiva no processo de redemocratização do país, através do apoio à maioria dos movimentos sociais urbanos e rurais, contribuindo com o aporte de recursos e estratégias de organização política e social, que culminaram com a queda do regime militar e a transição democrática no país (GOHN, 1998. p. 14).

As Organizações Não Governamentais tinham como principais objetivos a ampliação da política social, redemocratização do país, revitalização dos direitos civis e proteção de grupos sociais marginalizados. No país, as autênticas representações dos movimentos sociais no período da ditadura militar pós-1964 geralmente estão diretamente ligadas ao surgimento das ONGs, porque os partidos políticos e sindicatos estavam deformados e o povo, por carência da representatividade de suas entidades, buscou meios alternativos de representação (FERREIRA, 2005).

Falconer, Lucas e Salanon (1998) afirmam que, para as organizações do Terceiro Setor alcançarem a eficácia organizacional e se transformarem numa força permanente e sustentada a serviço da melhoria das condições humanas, será preciso vencer quatro desafios críticos que rondam o contexto atual das ONGs, os quais são explicados no Quadro 1.

Quadro 1 - Desafios críticos das ONGs e possíveis soluções

\begin{tabular}{|c|l|}
\hline Desafio da legitimidade & $\begin{array}{l}\text { As ONGs devem investir em disseminação de informações sobre o } \\
\text { Terceiro Setor e conscientizar a população sobre o papel desse setor } \\
\text { no mundo contemporâneo. }\end{array}$ \\
\hline Desafio da eficiência & $\begin{array}{l}\text { As ONGs devem mostrar a competência do setor para a sociedade, } \\
\text { aperfeiçoando os sistemas de administração e desempenho. }\end{array}$ \\
\hline Desafio da continuidade & $\begin{array}{l}\text { A continuidade torna-se necessária a partir do momento em que } \\
\text { as organizações necessitam sobreviver num mundo de recursos } \\
\text { cada vez mais escassos e de maior concorrência entre as próprias } \\
\text { organizações pertencentes ao Terceiro Setor. }\end{array}$ \\
\hline Desafio da colaboração & $\begin{array}{l}\text { Este desafio surge em três esferas distintas: colaboração com o } \\
\text { Estado, com o setor empresarial e com o setor das ONGs. }\end{array}$ \\
\hline
\end{tabular}

Fonte: Elaborado pelos autores (2016), com base em Falconer, Lucas e Salanon (1998).

As Organizações Não Governamentais, com o passar do tempo, sofreram várias mudanças estratégicas, estruturais e operacionais, que resultaram em um grande impacto na gestão (SILVA; SOUZA; LIMA, 2015). Vale salientar que tais mudanças decorrentes da atualidade exigem da gestão contemporânea uma adaptação das características de liderança para que a organização consiga se ajustar aos desafios encontrados no ambiente interno e externo. O modelo organizacional tem outra configuração, porque, na maioria dos casos, existem doadores financeiros para essas organizações, para o financiamento de projetos, fomento de serviços ou realização de pesquisas. O recurso financeiro também pode ser obtido por meio de subvenções ou contratos, ou mesmo pelo usuário, que pode financiar uma parcela dos gastos dos serviços prestados (HUDSON, 1999). 
Esse conceito define a continuidade organizacional das ONGs como a demanda por meio da combinação próxima da perfeição das fontes de financiamento e a relação da capacidade contínua de aquisição de recursos (materiais, financeiros ou humanos) que uma organização possui, aliada ao seu potencial de empregar os recursos obtidos com competência e foco em seus objetivos (CALEGARE; SILVA JUNIOR, 2009; FALCONER, ANDRES PABLO, 1999). Em meio a uma conjuntura de mudanças econômicas, políticas e sociais, as organizações sem fins lucrativos são desafiadas a se fortalecerem institucionalmente; dessa forma, o desenvolvimento organizacional passou a ser um ponto importante como condição da continuidade (OLIVEIRA, 2011). Acredita-se que, quando o conceito de continuidade é trazido ao Terceiro Setor, é utilizado para tratar da permanência e continuidade de longo prazo dos esforços realizados para atingir-se o desenvolvimento humano (KISIL, 2005). A continuidade de uma organização sem fins lucrativos não se restringe apenas a fatores que contribuem para continuidade financeira, mas deve considerar seu capital humano e um conjunto amplo de outros fatores.

\subsection{Liderança}

A liderança é um determinante para o sucesso das organizações. O conceito de liderança tem sido alvo de muitos estudos na esfera das ciências sociais e humanas. Nesse sentido, o processo de influenciar as atividades de um grupo organizado em seus esforços para o estabelecimento e alcance de metas pode ser entendido como liderança (STOGDILL, 1950). A preocupação com a liderança é tão antiga quanto o desenvolvimento da escrita e tem um aumento com a solidificação da política, porque, junto dessa preocupação, é exigido um nível maior de educação e treinamento específicos para os líderes políticos (FIEDLER, 1967). Compreender a liderança constitui umas das mais antigas tarefas humanas. No que diz respeito à questão organizacional e à atuação do gestor, o processo de liderar pode ser entendido como um conjunto de comportamentos que permite ao gestor influenciar sua equipe.

A primeira abordagem clássica sobre o tema originou a teoria dos traços, com ênfase nas qualidades dos bons líderes. Naquele momento, os estudos concentraram-se em identificar quem o é líder. Seguindo esse pensamento, as pesquisas dirigidas por essa teoria se preocuparam em mapear diferentes traços de personalidade que foram considerados como típicos de bons líderes, deixando de lado aspectos comportamentais e principalmente o relacionamento com os liderados. A abordagem comportamental e o estudo sobre os estilos de liderança feitos por Max Weber são responsáveis por diferenciar em três tipologias o comportamento do líder: liderança autoritária, liberal e democrática (SIQUEIRA; BINOTTO, 2008), como pode ser observado no Quadro 2:

Quadro 2 - Tipos de liderança na abordagem comportamental

\begin{tabular}{|l|l|}
\hline Autocrática & $\begin{array}{l}\text { Diretrizes fixadas pelo líder; } \\
\text { Ênfase na liderança; } \\
\text { Sem participação do grupo nas decisões. }\end{array}$ \\
\hline Democrática & $\begin{array}{l}\text { Ênfase no líder e nos liderados; } \\
\text { Diretrizes, técnicas e processos escolhidos pelo grupo; } \\
\text { Decisões do grupo assistidas pelo líder. }\end{array}$ \\
\hline Liberal & $\begin{array}{l}\text { Foco nos liderados; } \\
\text { Liberdade completa dos colaboradores na tomada de decisão. }\end{array}$ \\
\hline
\end{tabular}

Fonte: Elaborado pelos autores (2016), com base em Weber (2004). 
Essa abordagem destacava que a liderança podia ser aprendida por técnicas de desenvolvimento pessoal, que conduzissem a comportamentos de liderança adequados com base em um melhor entendimento do comportamento dos liderados (MATOS, 2012). No entanto, a liderança analisada como comportamento leva a críticas relacionadas às dificuldades encontradas em estabelecer os comportamentos apropriados, a desenvolver pessoas para tais comportamentos e à pouca importância da teoria às variáveis contextuais (CARDOSO; AMORIM, 2011).

Após a apresentação da abordagem comportamental, vale destacar a teoria da liderança contingencial, também conhecida como enfoques situacionais. Esta teoria reduziu a atenção do indivíduo (traços e comportamentos) e acentuou a importância do contexto e dos acontecimentos situacionais em torno do líder. Essa abordagem propõe que as organizações podem contar com bons líderes desde que haja treinamento adequado e um ambiente favorável onde possam agir com eficácia (BERGAMINI, 1994). Esse enfoque apresenta a ideia de que qualquer pessoa pode ser um bom líder desde que seja preparado para tal finalidade, trazendo outra variável ao determinar liderança com base nos fatores situacionais, o contexto e o meio envolvido.

Motta (2000) concorda com a afirmação de que a maioria das pessoas pode se tornar um líder, pois o aprendizado e a experiência implicam na aquisição das habilidades e competências necessárias para o exercício da liderança. Além disso, a liderança torna possível a interação pessoal e grupal para o alcance dos objetivos e das metas da organização, devendo ser almejada como função da gerência, apesar de outras pessoas na organização também exercê-la. Umas das discussões contemporâneas sobre a temática é diferenciar um líder de um gestor ou administrador; no entanto, entende-se que nem todos os líderes são administradores e nem todos os gestores são líderes. Nesta perspectiva, gestão e liderança atuam como ações distintas, porém, complementares, conforme características apontadas no quadro a seguir:

Quadro 3 - Diferenças entre liderar e gerenciar

\begin{tabular}{|l|l|}
\hline \multicolumn{1}{|c|}{ Liderar } & \multicolumn{1}{c|}{ Gerenciar } \\
\hline Gestão da mudança. & Gestão da complexidade. \\
\hline Alinhar as pessoas com visão e as estratégias. & Organizar e treinar pessoas. \\
\hline $\begin{array}{l}\text { Comunicar-se com diversas pessoas em várias } \\
\text { direções. }\end{array}$ & Desenvolver e comunicar planos de ação. \\
\hline Apresentar valores às pessoas. & Selecionar as pessoas de acordo com funções. \\
\hline Motivar pessoas. & Decidir a delegação de atividades. \\
\hline Apresentar visão do futuro. & Definir estrutura e hierarquia. \\
\hline Lidar com barreiras à mudança. & Controlar as pessoas e solucionar problemas. \\
\hline
\end{tabular}

Fonte: Adaptado de Zaleznik (2004).

Os direitos formais assegurados pela instituição aos gestores não são garantia de uma liderança eficaz, no entanto, a liderança que surge fora da estrutura formal da organização é tão importante quanto a formal (ROBBINS, 2005). Segundo Schein (2004), se alguém deseja distinguir liderança de gestão ou administração, pode argumentar que a liderança cria e molda as transformações culturais, enquanto a gestão e a administração atuam dentro de uma cultura. É primordial que o líder possua conhecimento e capacidade para desenvolver com maturidade sua influência sobre o grupo; assim, é preciso que ele tenha um conhecimento superior em 
relação à própria experiência, dinamismo e entusiasmo para realizar as tarefas (BERGAMINI, 1994). No estudo do tema de liderança no contexto organizacional, seus efeitos em tal contexto têm sido investigados desde a origem das abordagens sistemáticas da Administração Moderna (VIZEU, 2011).

Apesar de as ações do líder influenciarem as ações da equipe, a perpetuação da missão organizacional advém das ações dos liderados. Essa questão vem sendo enfatizada na maioria das teorias de liderança, mostrando a necessidade de muitos estudos se voltarem para as habilidades e a disposição do líder em incentivar a equipe a realizar determinada atividade.

\subsubsection{Perfis de liderança}

Após anos de estudos sobre liderança, atualmente ainda se levantam discussões sobre a questão: se os líderes nascem líderes ou aprendem a sê-lo. A resposta é que ambas as afirmações estão corretas (GOLEMAN, 2000). Entretanto, denominações como carismática, transformacional, visionária e transacional são adicionadas no contexto de liderança no qual podem ser agrupadas como "nova liderança" (BRYMAN, 2009). Nesse sentido, para o desenvolvimento da pesquisa, serão abordadas as teorias de liderança transacional, transformacional e carismática. A liderança transformacional pode ser definida como o processo pelo qual o líder sensibiliza os seus seguidores para a direção correta, com motivação para alcançar um desempenho acima das expectativas (ZALEZNIK, 2004). Essa liderança está baseada no efeito do líder sobre os seguidores e no comportamento evidenciado por estes para alcançar esse efeito, proporcionando um nível superior de compromisso e identificação com os objetivos do líder e da organização por parte dos liderados (BASS, 1990). As ações do líder funcionam como modelo motivacional de relacionamento interpessoal, cuja influência de um indivíduo sobre outro ocorre em uma via de mão dupla, executando um clima de respeito mútuo. São evidenciadas cinco importantes características intrinsecamente ligadas. São elas: influência idealizada, carisma, capacidade de motivar, capacidade de estimular intelectualmente os subordinados e a preocupação sobre as necessidades individuais dos seus colaboradores (NAYAK; SALOVAARA; WADE, 2019).

A liderança transacional baseia-se no esclarecimento de expectativas, na adoção de recompensas e punições de acordo com o desempenho do colaborador. Este tipo de liderança é sustentado no processo de reconhecimento associado (MATOS, 2012). Os líderes transacionais evidenciam três pilares: recompensa contingente, gestão ativa por exceção (os seguidores são conduzidos por regras de conformidade, evitando erros) e gestão passiva por exceção (os líderes transacionais apenas intervêm quando necessário e quando os erros verificados são significativos). Existem vários estilos de liderança, mas a dicotomia entre liderança transformacional e transacional tem merecido mais atenção (MATOS, 2012).

A teoria da liderança carismática afirma que os seguidores, ao observarem determinado comportamento do líder, atribuem a ele capacidade heroica e admirável (ROBBINS, 2005). Os achados do autor indicam que colaboradores coordenados por líderes carismáticos exibiram desempenho melhor que os liderados por aqueles que não possuíam essas características. A característica do líder carismático está associada à capacidade de comunicação, sobretudo na perspectiva emocional. Esta característica permite que o grupo liderado se identifique, partilhe do sonho do líder e o vivencie tão ou mais sentidamente do que o próprio líder (FRY et al., 2017). Nesse caso, atingir alto nível de desempenho não é necessariamente exigido, ou seja, o carisma 
demonstra ser mais pertinente quando as atividades desempenhadas pelos liderados precisam de um componente ideológico ou quando um ambiente envolve um elevado grau de incerteza ou tensão; no entanto, o carisma possui fatores limitantes, como a ideologia de incerteza ambiental e o nível da organização.

Dessa forma, entende-se que o papel do líder não se limita apenas a construir ou seguir uma cultura organizacional, seu objetivo vai além, mantendo uma cultura eficaz e realizando mudanças culturais. Percebe-se, assim, que a tomada de decisão é uma competência de liderança essencial para a continuidade da missão da organização (YOUNG, 2001). Por outro lado, Schein (2004) argumenta que a única importância real que os líderes podem fazer é a de criar e gerenciar a cultura, e que o talento único dos líderes está relacionado a sua capacidade de compreender e trabalhar com a cultura; no entanto, a liderança pode também destruir a cultura, principalmente quando o líder é visto como disfuncional.

\subsubsection{Liderança e estratégia no terceiro setor}

Nas Organizações Não Governamentais, é essencial que a liderança tenha uma visão voltada para o futuro, esteja preocupada com a necessidade de seus beneficiários e disponha de bom relacionamento com os doadores (HUDSON, 1999). Pode-se considerar que a gestão e a liderança, quando conectadas, trabalham de maneira eficaz em diversos níveis organizacionais: nível estratégico; nível da própria gestão e nível operacional (MAÑAS; MEDEIROS, 2012). A estratégia pode ser definida como: "um padrão, isto é, consistência em comportamento ao longo do tempo" (MINTZBERG et al., 2006, p. 17). Em consonância com essa afirmação, Porter (2005, p. 63) complementa o conceito quando expõe que:

Estratégia é criar uma posição exclusiva e valiosa, envolvendo um diferente conjunto de atividades [...] é a criação de compatibilidade entre as atividades da empresa. Seu êxito depende do bom desempenho de muitas atividades e da integração entre elas.

A liderança mais presente no Terceiro Setor é aquela mais carismática e inspiradora, que motiva todos os colaboradores, enfatizando a importância e o valor dos seus objetivos (BARROS, 2002). Complementando a ideia anterior, Costa (1992) explica que o gestor de uma entidade social é julgado a partir dos seguintes critérios: agilidade mental, criatividade, capacidade de organização, liderança, profissionalismo, conhecimento econômico, disposição para aprender cada vez mais e sempre, iniciativa, determinação, cuidado, resistência, capacidade de cooperação, sociabilidade, confiabilidade, senso crítico, responsabilidade, entre outros. Na visão de Tenório (2003), nas organizações contemporâneas não basta delegar autoridade apenas formalmente, mas se faz necessário que se exerça a gerência com liderança.

A hesitação das Organizações Não Governamentais em relação ao uso de modelos gerenciais tradicionais se deve ao fato de que, na cultura organizacional dessas instituições, a missão é voltada a questões sociais e há alto grau de informalidade nas relações sociais, sendo estas, portanto, as principais causas da aversão dos modelos gerenciais por parte dessas organizações (MINTZBERG et al., 2006). Dessa forma, compete à liderança não só gerenciar as estratégias existentes, mas propor novas estratégias, monitorar o processo de implementação e avaliar os resultados. Observam-se ainda as Estratégias Planejadas, derivadas de planos formais: intenções precisas existem e são formuladas e articuladas pela liderança principal (ZANNI, 2005). 


\section{METODOLOGIA}

Do ponto de vista dos objetivos, esta pesquisa possui caráter exploratório e descritivo. De acordo com Gil (2008), esse tipo de pesquisa envolve o levantamento do estado da arte, pela revisão bibliográfica, e, além disso, envolve o estudo dos atores relacionados ao processo pesquisado, para que a vivência com o problema possa estimular e facilitar a compreensão do fato. Quanto à abordagem do problema, esta pesquisa pode ser classificada como qualitativa. De acordo com os procedimentos técnicos, a pesquisa será classificada como estudo de campo, uma vez que serão realizadas entrevistas e visitas nas organizações que farão parte da amostra. Segundo (RICHARDSON, 1999), esse tipo de pesquisa explora particularmente as técnicas de observação e entrevistas, devido à propriedade com que esses instrumentos penetram na complexidade de um problema. Além disso, este estudo também contemplará uma análise documental e bibliográfica.

Quanto à escolha do universo e amostra, buscou-se delimitar às Organizações Não Governamentais filiadas à Associação Brasileira das Organizações Não Governamentais (ABONG) e que possuam sede no estado de Pernambuco. O universo da pesquisa foi composto por três organizações. A área de atuação das ONGs foi utilizada como critério de escolha da amostra, pois demonstra proximidade com as áreas afins da área de administração. Para serem entrevistados, foram escolhidos um líder (diretor, gestor ou coordenador) e um liderado (que trabalhasse próximo ao líder) de cada instituição. Isso porque cada um dos envolvidos pode apresentar perspectivas diferentes, o que contribui para enriquecer a análise e obter um aprofundamento dos questionamentos apresentados.

A técnica de coleta de dados atendeu às recomendações relacionadas à pesquisa qualitativa. Foi utilizada a triangulação de dados, que, na perspectiva do campo das ciências sociais, corresponde a uma estratégia de pesquisa baseada na utilização de diversos métodos para investigar um mesmo fenômeno (VERGARA, 2004). As diferentes fontes utilizadas para coleta de dados foram: documentos institucionais; entrevistas semiestruturadas com os gestores das ONGs; entrevistas com os colaboradores das ONGs. Foram realizadas oito entrevistas abertas, mas focalizadas e em profundidade com pessoas-chave, para compreensão dos temas de liderança e estratégia. Dessa forma, a entrevista semiestruturada foi realizada mediante a utilização de um roteiro, com 26 questões abertas, com a finalidade de nortear a discussão durante todo o desenvolvimento do trabalho. Além da entrevista, foram coletados dados específicos para o desenvolvimento do trabalho em documentos disponibilizados pelas ONGs, como: meios de divulgação de ações e projetos das Organizações; sítio das ONGs; relatórios em revista da mídia impressa; panfletos informativos; livros publicados a respeito da organização; informes internos.

\section{RESULTADOS}

Dentro dos critérios utilizados para seleção da amostra, a entrevista foi aplicada em três Organizações Não Governamentais sediadas na região metropolitana do Recife. As instituições não terão seus nomes divulgados; no entanto, serão apresentadas como: ONG 1, ONG 2 e ONG 3 no decorrer do trabalho. A descrição de suas características será apresentada a seguir: 
Quadro 2 - Apresentação ONG 1

\begin{tabular}{|c|c|}
\hline & ONG 1 \\
\hline \multicolumn{2}{|c|}{ Ano de Constituição - 1993} \\
\hline Região de Atuação: Nordeste. & Utiliza Trabalho Voluntário: Sim. \\
\hline $\begin{array}{l}\text { Missão: plantar mais vida para um mundo } \\
\text { melhor, desenvolvendo a agricultura familiar } \\
\text { agroecológica e a cidadania. }\end{array}$ & $\begin{array}{l}\text { Principal âmbito de atuação: } \\
\text { nacional; regional; estadual; municipal. }\end{array}$ \\
\hline $\begin{array}{l}\text { Áreas Temáticas de Atuação: } \\
\text { Agricultura; Meio Ambiente; Economia Solidári } \\
\text { Comunicação; Fortalecimento de outras ONGs } \\
\text { Movimentos Populares; Segurança Alimentar e } \\
\text { Agroecologia. }\end{array}$ & $\begin{array}{l}\text { Principais Beneficiários / Público-Alvo: } \\
\text { trabalhadores(as) urbanos(as) / sindicatos } \\
\text { urbanos; mulheres; jovens; comunidades } \\
\text { tradicionais; lideranças e educadores(as) } \\
\text { populares. }\end{array}$ \\
\hline \multicolumn{2}{|c|}{ ONG 2} \\
\hline \multicolumn{2}{|c|}{ Ano de Constituição: 2000} \\
\hline Região de Atuação: Nordeste. & Utiliza Trabalho Voluntário: Sim \\
\hline $\begin{array}{l}\text { Missão: gerar e divulgar soluções estratégicas } \\
\text { para a conservação da biodiversidade, } \\
\text { mediante ciência, formação de recursos } \\
\text { humanos e diálogo com a sociedade. }\end{array}$ & $\begin{array}{l}\text { Principal âmbito de atuação: } \\
\text { internacional; nacional; regional; estadual e } \\
\text { municipal. }\end{array}$ \\
\hline $\begin{array}{l}\text { Áreas Temáticas de Atuação: } \\
\text { Meio Ambiente; Fortalecimento de outras } \\
\text { ONGs / Movimentos Populares; Restauração } \\
\text { Ambiental; Conservação Ambiental. }\end{array}$ & $\begin{array}{l}\text { Principais Beneficiários / Público-Alvo: } \\
\text { População em geral; trabalhadores(as) rurais / } \\
\text { sindicatos de trabalhadores(as) rurais; organizações } \\
\text { populares / movimentos sociais e outras ONGs. }\end{array}$ \\
\hline \multicolumn{2}{|r|}{ ONG 3} \\
\hline \multicolumn{2}{|c|}{ Ano de Constituição: 1988} \\
\hline Região de Atuação: Nordeste - Centro-Oeste. & Utiliza Trabalho Voluntário: Sim. \\
\hline $\begin{array}{l}\text { Missão: promover a melhoria da qualidade } \\
\text { de vida da população, com ênfase no direito } \\
\text { humano à saúde. }\end{array}$ & $\begin{array}{l}\text { Principal âmbito de atuação: Nacional; Regional; } \\
\text { Estadual e Municipal }\end{array}$ \\
\hline $\begin{array}{l}\text { Áreas Temáticas de Atuação: } \\
\text { Saúde; Meio Ambiente; Relações de Gênero; } \\
\text { Crianças e Adolescentes; Questão Indígena. }\end{array}$ & $\begin{array}{l}\text { Principais Beneficiários / Público-Alvo: } \\
\text { crianças e adolescentes; organizações populares / } \\
\text { movimentos sociais; mulheres; negros(as) e povos } \\
\text { indígenas. }\end{array}$ \\
\hline
\end{tabular}

Fonte: Elaborado pelos autores (2017), com base em dados institucionais.

De acordo com o líder da ONG 1, a motivação relaciona-se diretamente aos valores e princípios organizacionais e com o modelo de sociedade em que se acredita. Inclusive, a ONG trabalha na formação política dos beneficiários com o objetivo de transformar a sociedade. Em concordância com o que foi dito, o liderado da ONG 1 complementou que o líder busca incentivar o diálogo constante e monitoramento das ações tanto no dia a dia quanto nas reuniões de avalições. A flexibilidade foi apontada como uma característica que possibilita uma relação harmônica com a equipe, junto da disposição a ouvir e entender as limitações da equipe.

O líder da ONG 1 mencionou que acredita exercer influência intelectual na equipe, visto que é seu papel provocar e questionar, apoiar e nortear as ações da equipe, mas sempre priorizando o diálogo. O líder comentou que não procura ser um modelo de comportamento, mas busca agir naturalmente, pois a equipe está inserida em um processo constante de construção de conhecimento, o qual deve ser construído em conjunto. Segundo o liderado da ONG 1, o líder busca incentivar a equipe provocando e problematizando uma reflexão e procura utilizar a reflexão 
coletiva para o redirecionamento. Foi declarado que o líder pode ser considerado um exemplo, levando-se em conta seu comportamento, principalmente na perspectiva provocativa de fazer a equipe refletir sobre as ações realizadas, sob uma perspectiva política, e entender a conjuntura nacional. Ele também demonstra preocupação com as necessidades individuais dos funcionários, pois possuem perspectiva em comum, que é militar por uma causa em que se acredita.

O líder da ONG 2 informou que busca incentivar dentro da organização alguns valores, princípios e atitudes como: sinceridade, qualidade e proatividade. Acredita exercer influência intelectual e valoriza o conhecimento, pois, para ele, é um alicerce fundamental para que a instituição dê certo. Segundo o liderado da ONG 2, o incentivo do líder é percebido principalmente por ele não ser centralizador e delegar as atividades de acordo com as expertises de cada funcionário. O liderado comentou ainda que considera que o líder exerce influência intelectual, pois ele procura incentivar a escrita e publicação de artigos, compartilha material de leitura e se atualiza sobre a temática de atuação.

Divergentemente do que foi dito acima, o líder da ONG 2 informou que não acredita ser um exemplo quanto a comportamento, pois não segue padrões de "figura de liderança", e afirma que existem outras formas de cativar as pessoas, que não sejam tão "moldadas". Porém busca incentivar os comportamentos considerados essenciais, como: vontade de trabalhar, energia, sinceridade e vontade de dar certo. Para o liderado da ONG 2, o líder demonstra preocupação com as necessidades individuais dos funcionários, de modo mais informal, pois faz questão de mostrar reconhecimento pelo trabalho e flexibilizar o horário de realização das atividades, além de ser muito presente. O líder, em conformidade com o que foi dito, comentou que se preocupa com as necessidades de seus liderados e busca sempre conversar com a equipe, pois os considera amigos.

Referente ao tipo de valores/princípios e atitudes incentivadas dentro da organização, o líder da ONG 3 declarou que procura incentivar uma convivência pacífica dentro da instituição e evita competição interna e comentários desnecessários. O liderado, em concordância, acrescentou que a liderança busca também incentivar a união da equipe e que cada um assuma a responsabilidade de desempenhar aquilo que foi demandado. O líder da ONG 3 acredita que colabora um pouco em relação à influência intelectual, pois tem conhecimento na área de saúde e segurança alimentar, assim como experiência, pois sempre desempenhou atividades na comunidade. Afirmou ainda que se preocupa em ser um exemplo, principalmente quanto ao comportamento, e que valoriza sempre o diálogo. O liderado concorda, ao considerar que o líder exerce poder de influência intelectual, e declara ainda que o considera exemplo de comportamento, pois o líder tem uma história de vida de luta, procura por seus direitos e não se acomoda.

\subsection{Aspectos relacionados à liderança transacional}

Foi informado pelo líder da ONG 1 que a instituição possui metas bem estabelecidas, baseadas no planejamento estratégico, tanto as metas individuais quanto as metas coletivas. As metas não são iguais para todos e é realizado monitoramentos que possibilita certa flexibilidade. As metas dos liderados são monitoradas com a finalidade de medir o impacto da ação institucional na sociedade. Desse modo, diferentemente de uma empresa privada, o funcionário não é demitido caso não obtenha o desempenho esperado; ao invés disso, procura-se entender o motivo de o desempenho não ter sido alcançado. As possíveis ocorrências de erros são onduzidas 
levando em conta o tipo de erro. Tal fato justifica-se por se tratar de uma organização social que possui como base uma série de princípios. De todo modo, procura-se conversar e ouvir as partes envolvidas, é realizado o levantamento de todo o processo para entender o porquê.

Segundo o liderado da ONG 1, as metas e os objetivos são construídos coletivamente, o que permite que a equipe tenha um entendimento do que está sendo proposto. Mas as metas e os objetivos são estabelecidos de modo suave e são traçados de acordo com as propostas dos projetos a serem realizados, sendo vistos mais como uma estratégia para executar o que foi proposto a se realizar. Assim, a coordenação vai gerindo o processo para que ele aconteça da forma mais coerente possível. De acordo com o líder da ONG 2, não são estabelecidas metas de desempenho para a equipe; no entanto, existem produtos (prestação de serviço) a serem entregues e prazos dos projetos que devem ser cumpridos, pois são compromissos assumidos com os doadores e parceiros.

Inteirando o que foi dito acima, o liderado da ONG 2 relatou que as metas não são acompanhadas como modo de quantificação de desempenho, mas utilizadas para acompanhar se os objetivos propostos nos projetos foram alcançados. E informou que as possíveis ocorrências de erros, reclamações e indisciplinas dos funcionários são conduzidas pelo líder com diálogo. Segundo o líder da ONG 2, o grau de entrosamento da equipe permite entender quem tem compromisso e quer continuar realizando as atividades. Desse modo, no caso de ocorrências de erros, em um relatório, por exemplo, é realizada uma cobrança para o funcionário decidir se ele se enquadra nos padrões de exigências necessários para realizar as ações ou se desiste. De acordo com o líder da ONG 3, as metas são estabelecidas para a equipe de forma clara, assim a equipe pode ficar ciente do que deve ser realizado. As metas e o desempenho da equipe são acompanhados como resultado, no entanto, a instituição ainda não realiza avaliação individual.

Segundo o liderado da ONG 3, a liderança costuma estabelecer metas e objetivos, a equipe é cobrada caso ocorra atrasos na realização das atividades ou entrega dos relatórios, pois erros nessas ações podem prejudicar o recebimento de recursos e atrasar o andamento de todas as atividades institucionais. Para o líder da ONG 3, as possíveis ocorrência de erros, reclamações e indisciplinas dos funcionários são conduzidas na base do diálogo. Mas, no caso de erros por não cumprir uma meta, é realizada uma avaliação e estipula-se um prazo para que ocorra uma melhora no desempenho do funcionário. Quanto a esse assunto, o liderado acrescentou que a liderança chama para conversar com a coordenação; caso o problema se prolongue e seja necessária a substituição do funcionário, a alteração é decidida pela coordenação junto da administração.

Segundo Robbins (2005), líderes transacionais são aqueles que conduzem e motivam seus seguidores na direção das metas estabelecidas por meio do esclarecimento dos papéis e das exigências das tarefas. Ele apresenta as seguintes características: recompensa por contingentenegocia a troca de recompensas por esforço, prometendo recompensas pelo bom desempenho, além de reconhecer as conquistas; administração por percepção (ativa) - procura e observa desvios das regras e dos padrões, tomando as atitudes corretivas necessárias; administração por exceção (passiva) - intervém quando os padrões não são alcançados; e Laissez-Faire - abre mão das responsabilidades, evitando tomar decisões. 


\subsection{Aspectos relacionados à liderança carismática}

De acordo com o líder da ONG 1, a melhor coisa da liderança é tentar dar exemplo pedagógico. Assim, ele busca observar a equipe, monitorar as metas e estar sempre em diálogo com a equipe. O líder frisou o quanto é importante a troca de informação constante entre a equipe e que ele preza por essa liderança de estar junto. O líder da ONG 1 acredita que não existe líder nato, mas que a liderança pode ser ensinada; por isso, futuramente, a instituição terá formações para liderança para os que atuam nas coordenações de projetos. Ele sente satisfação em desempenhar a liderança, apesar de admitir que a responsabilidade aumenta assim como a quantidade de atividades; no entanto, sua satisfação reflete nos resultados apresentados e também no feedback da direção. De acordo com o liderado da ONG 1, a gestão é observada pela perspectiva da reflexão construtiva. São percebidas características como tranquilidade e diálogo, que têm uma influência positiva e a valorização das atividades que são realizadas. O liderado da ONG 1 considera que o líder se sente à vontade ao desempenhar seu papel, pois tem um perfil de gestor, busca compreender a metodologia institucional, procura por formação que complementem as práticas das atividades e está presente em várias etapas dos processos, com disposição para acompanhar as atividades.

Segundo o líder da ONG 2, a equipe está bem adaptada ao modo de trabalho do líder, o que permite uma concordância entre as ações que devem ser realizadas e os resultados esperados. É perceptível a predisposição da equipe não só em absorver o que é proposto, mas também em comprar as ideias e acrescentar melhorias. Do ponto de vista do liderado da ONG 2, o líder apresenta característica de influência em conduzir a equipe. Foram pontuadas algumas características, como: não ser omisso, ser comunicativo e sensitivo. Essas características são evidenciadas no acompanhamento das atividades, no incentivo à equipe para executar as ações e ao inspirar os funcionários a chegar no mesmo patamar de conhecimento que ele.

O líder da ONG 2 afirmou que se sente feliz ao desempenhar o papel de liderança, pois trabalha com o que gosta, e entende que a função vem acompanhada de bastante responsabilidade; mesmo assim, sente prazer e considera que vale a pena desempenhar seu papel. Referente a esse ponto, o liderado acrescentou que o fato de fazer o que gosta e a capacidade de comunicação são fatores que evidenciam que o líder se sente bastante à vontade ao desempenhar seu papel. O líder da ONG 3 declarou que não tenta influenciar ao conduzir a equipe para realizar os objetivos propostos, pois prefere que a equipe faça por conta própria o que foi decidido. O líder não se sente à vontade em exercer o seu papel, por considerar sua atividade muito burocrática, e esclarece que tem preferência por atividades técnicas. O liderado explicou que a liderança exige resultados, mesmo que esses não sejam especificados, além de incentivar a realização das atividades de modo colaborativo. E considera que cada um da equipe é avaliado pelos resultados demonstrados.

Por sua vez, o liderado da ONG 3 relatou que considera o líder com capacidade de influência ao conduzir a equipe, pois a incentiva a ter responsabilidade, iniciativa e independência nas ações realizadas e, mesmo assim, sempre vai cobrar aquilo que tinha capacidade de ser realizado. Informou que a liderança exige resultados, mesmo que esses não sejam especificados, e que incentiva a realização das atividades de modo colaborativo. Considera, ainda, que cada um da equipe é avaliado pelos resultados demonstrados. Ao declarar sobre como se sente ao exercer o papel de liderança, o líder da ONG 3 expressou que não se sente à vontade em exercer 
o seu papel, por considerar sua atividade muito burocrática, e esclarece que tem preferência por atividades técnicas, com as quais atuou por vários anos. Sobre esse ponto, o liderado discordou do líder, pois considera que o líder se sente à vontade ao desempenhar seu papel.

\section{CONSIDERAÇÕES FINAIS}

Este trabalho se propôs a analisar os perfis de liderança dos gestores e as práticas de gestão estratégica nas Organizações Não Governamentais. Com base nas informações coletadas de entrevistas aplicadas a líder e liderado de três ONGs, esta pesquisa explorou o perfil de liderança e as práticas de gestão estratégica. Vale ressalvar que as contribuições geradas na análise desse trabalho não podem ser atribuídas de maneira generalizada, mas sim em relação ao corpus da pesquisa. Ao analisar os perfis de liderança dos gestores das ONGs, observou-se que a ONG 1 evidenciou aspectos predominantes da liderança transformacional. Entre as características explícitas, pode-se citar: encorajar a equipe a olhar para o futuro; incentivo à problematização e reflexão das ações organizacionais; e estímulo intelectual.

A ONG 2 demonstrou características que compreendem traços da liderança carismática. Foram evidenciados aspectos como: o relacionamento entre líder e liderado transcende o ambiente organizacional; elevada influência de pessoas; e grande capacidade de comunicação para que o grupo alcance as metas institucionais propostas.

Por sua vez, a ONG 3 expôs aspectos dominantes de características da liderança transacional. Entre os traços marcantes, pode-se citar a liderança diretiva voltada para execução dos processos; prevenção de possíveis erros e aplicação de ações corretivas quando não se cumpre o que foi estabelecido. No entanto, foi constatado que o perfil de liderança se assemelha à liderança transformacional. Também foram expostos alguns atributos que não se aproximam das lideranças pesquisadas que foram estudadas e são consideradas particularidades individuais. A liderança da ONG 2 apresentou características semelhantes à liderança transformacional e carismática; no entanto, houve predominância de aspectos de liderança carismática. Foram apresentados alguns traços que não pertenciam aos perfis pesquisados e são considerados atributos peculiares do líder.

\section{REFERÊNCIAS}

ALBUQUERQUE, A. C. C. DE. Terceiro Setor: História e Gestão de Organizações. 2. ed. São Paulo: Summus Editorial, 2006.

BARROS, M. Uma Proposta de Tipologia Organizacional Comparada das Organizações Não- Governamentais. Salvador: [s.n.], 2002.

BASS, B. M. From Transactional to Iransformational Leadership: Learning to Share the Vision. Organizational Dynamics, v. 18, n. 3, p. 19-32, 1990.

BERGAMINI, C. W. Liderança: A Administração do Sentido. RAE - Revista de Administração de Empresas, v. 34, n. 3, p. 102-14, 1994.

BEZERRA, J. M. D. C.; ARAÚJO, M. A. D. DE. Planejamento estratégico em ONGs e sustentabilidade o caso da Casa de Passagem. RAP - Revista de Administração Pública, v. 38, n. 5, p. 799-816, 2004.

BRYMAN, A. Liderança nas organizações. 3. ed. São Paulo: Editora Atlas, 2009. 
CALEGARE, M. G. A.; SILVA JUNIOR, N. A "construção" do terceiro setor no Brasil: da questão social à organizacional. Revista Psicologia Política, v. 9, n. 17, p. 129-48, 2009.

CARDOSO, P.; AMORIM, M. Traços, comportamentos e contextos: desenvolvimento de líderes em ONG, a "experiência SIFE" no Centro Universitário do Pará. Revista de Carreiras \& Pessoas, v. 1, 2011.

COSTA, W. M. DA. Geografia Política e Geopolítica: discursos sobre o território e o poder. 1992.

FALCONER, A. P. A promessa do terceiro setor: um estudo sobre a construção do papel das organizações sem fins lucrativos e do seu campo de gestão, 1999.

FALCONER, A. P.; LUCAS, A.; SALAMON, L. A emergência do terceiro setor - uma revolução associativa global. Revista de administração, v. 33, n. 1, p. 5-11, 1998.

FERNANDES, R. C. Privado porém público: o terceiro setor na América Latina. 2. ed. Rio de Janeiro: Civicus, 1994.

FERREIRA, V. C. P. ONGs no Brasil: um estudo sobre suas características e fatores que têm Induzido seu crescimento. Rio de Janeiro: Fundação Getúlio Vargas, 2005.

FIEDLER, F. E. A theory of leadership effectiveness. Mcgraw-hill series in management, 1967.

FISCHER, R. M. O desafio da colaboração: práticas de responsabilidade social entre empresas e terceiro setor. São Paulo: Editora Gente, 2002.

FRY, L. W. et al. Spiritual leadership as a model for performance excellence: a study of Baldrige award recipients. Journal of Management, Spirituality \& Religion, v. 14, n. 1, p. 22-47, 2 jan. 2017. Disponível em: https://www.tandfonline.com/doi/full/10.1080/14766086.2016.1202130.

GIL, A. C. Métodos e técnicas de pesquisa social. 6. ed. São Paulo: Atlas, 2008.

GOHN, M. DA G. O novo associativismo e o Terceiro Setor. Serviço Social \& Sociedade, v. 58, 1998.

GOLEMAN, D. Leadership That Gets Results. Harvard Business Review, 2000.

HUDSON, M. Administrando Organizações do Terceiro Setor: o desafio de administrar sem receita. São Paulo: Editora Makron Books, 1999.

KISIL, M. Organização social e desenvolvimento sustentável: projetos de base comunitária. São Paulo: Editora Paz e Terra S.A, 2005.

LANDIM, L. A invenção das ONGs: do serviço invisível à profissão impossível. Universidade Federal do Rio de Janeiro, 1993.

MAÑAS, A. V.; MEDEIROS, E. E. Terceiro setor: um estudo sobre a sua importância no processo de desenvolvimento sócio-econômico. Perspectivas em Gestão \& Conhecimento, v. 2, n. 2, p. 15-29, 2012.

MATOS, P. G. Liderança nas PME e sua Influência no Agradecimentos. Covilhã: Universidade da Beira Interior, 2012.

MINTZBERG, H. et al. O processo da estratégia: conceitos, contextos e casos selecionados. 4. ed. Porto Alegre: Bookman, 2006. 
MOTTA, P. R. Transformção organizacional: a teoria, e a prática de inovar. [S.I.]: Qualitymark Editora Ltda, 2000.

NAYAK, G.; SALOVAARA, I. M.; WADE, J. Self-Regulated Learning in Refugee Entrepreneurship Education: A University-Based Program for Tibetan Entrepreneurs in India. Diaspora, Indigenous, and Minority Education, v. 13, n. 2, p. 81-96, 3 abr. 2019. Disponível em: https://www.tandfonline.com/doi/full/10.10 80/15595692.2018.1557632.

OLIVEIRA, W. A. DE. Terceiro Setor e o Desafio da Sustentabilidade: estudo Salvador-Bahia-Brasil, 2011. Coimbra: Universidade de Coimbra, 2011.

OUIMET, G. As armadilhas dos paradigmas da liderança. Revista de Administração de Empresas, v. 42, n. 2, p. 8-16, 2002.

PORTER, M. E. Estratégia competitiva: técnicas para a análise da indústria e da concorrência. 11. ed. Rio de Janeiro: Campus, 2005.

RICHARDSON, R. J. Pesquisa Social: métodos e técnicas. 3 ed. ed. São Paulo: Editora Atlas, 1999.

ROBBINS, S. P. Comportamento Organizacional. 11. ed. São Paulo: Pearson Prentice Hall, 2005.

SCHEIN, E. H. Organizational Culture and Leadership. 3. ed. San Francisco: Third Edition, 2004. v. 7.

SILVA, B. L. E; SOUZA, V. V.; LIMA, R. P. Aspectos da liderança nas organizações sem fins lucrativos: uma pesquisa de campo com os líderes dos projetos Tamar e Instituto Ethos. Resende: [s.n.], 2015.

SIQUEIRA, E. S.; BINOTTO, E. A liderança no Terceiro Setor: um perfil de atuação. EnEO, n. 1, 2008.

STOGDILL, R. M. Leadership, membership and organization. Psychological bulletin, v. 47, n. 1, p. 1, 1950.

TACHIZAWA, T.; POZO, H.; ALVES, J. A. F. Formulação de um plano estratégico em instituições do Terceiro Setor: o caso de uma ONG de pequeno porte. REUNA, v. 17, n. 3, p. 53-72, 2012.

TENÓRIO, F. G. Gestão de ONG: principais funções gerenciais. 9. ed. Rio de Janeiro: Editora FGV, 2003.

VergarA, S. C. Métodos de Pesquisa em Administração. 2. ed. São Paulo, SP: Editora Atlas, 2004.

VIZEU, F. Uma aproximação entre liderança transformacional e Teoria da Ação Comunicativa. RAM. Revista de Administração Mackenzie, v. 12, n. 1, p. 53-81, 2011.

WEBER, M. Economia e Sociedade: fundamentos da sociologia compreensiva. São Paulo: Editora Uiversidade de Brasília, 2004.

YOUNG, D. R. Organizational Identity in Nonprofit Organizations: Strategic and Structural Implications. Nonprofit Management and Leadership, v. 12, n. 2, p. 139-57, 2001.

ZALEZNIK, A. Managers and Leaders: are they different? Harvard Business Review on Leadership, 2004.

ZANNI, P. P. Estudo exploratório sobre a formação da estratégia em organizações do Terceiro Setor. São Paulo: Fundação Getúlio Vargas, 2005. 


\section{Sobre os autores:}

Ana Paula Santana Melo: Mestre em Administração e Desenvolvimento Rural pela Universidade Federal Rural de Pernambuco (UFRPE). E-mail: paulasantanademelo@gmail.com, Orcid: http://orcid.org/0000-0003-0599-1117

Marcelo da Costa Borba: Doutorando em Agronegócios pela Universidade Federal do Rio Grande do Sul (UFRGS). E-mail: marcelodcborba@gmail.com, Orcid: http://orcid.org/0000-0002-7173-1199

Maria Irae Souza Correia: Doutora em Administração pela Universidade Federal de Pernambuco (UFPE). E-mail: mariairae@hotmail.com, Orcid: http://orcid.org/0000-0002-8958-6583

Romilson Marques Cabral: Doutor em Administração pela Universidade Federal da Bahia (UFPBA). E-mail: romilsonmarquescabral10@gmail.com, Orcid: http://orcid.org/0000-0002-8851-3956 